\title{
Online commentary in acute medical visits: a method of shaping patient expectations
}

\author{
John Heritage $^{\mathrm{a}, *}$, Tanya Stivers ${ }^{\mathrm{b}}$ \\ ${ }^{a}$ Department of Sociology, UCLA, Los Angeles, CA 90095, USA \\ ${ }^{\mathrm{b}}$ Department of Applied Linguistics, UCLA, Los Angeles, CA 90095, USA
}

\begin{abstract}
This paper conceptualizes a type of physician communication, termed 'online commentary'. Online commentary is talk that describes what the physician is seeing, feeling or hearing during physical examination of the patient. Some dimensions of online commentary are described, and its functions in routine and acute medical consultations are distinguished. Using a case study method, the paper focuses on the role of online commentary in pre-empting patient resistance to upcoming 'no problem' diagnostic evaluations which could delegitimize patients' decisions to seek medical assistance, or deprive them of anticipated medical benefits. It is hypothesized that this role for online commentary may be associated with successful physician resistance to implicit or explicit patient demands for inappropriate antibiotic medication. (C) 1999 Elsevier Science Ltd. All rights reserved.
\end{abstract}

Keywords: Conversation analysis; Physician-patient communication; antibiotic prescribing

\section{Introduction}

When physicians examine patients, they may engage in several forms of communication. Prominent among these are, first, directives instructing patient actions during the examination and, second, questions about

*Corresponding author. Tel.: +1-310-206-5216; fax: +1310-206-9838.

E-mail address: heritage@soc.ucla.edu (J. Heritage)

${ }^{1}$ Transcription conventions for the data presented in this paper are contained in Atkinson and Heritage (1984) and Ochs et al. (1996). sensations associated with the examination itself. A third and relatively under-researched type of physician communication offers insight into different aspects of the physical examination itself. This communication is produced 'online' and gives contemporaneous information concerning the procedures, findings, and prospective diagnostic implications of the examination in progress.

We can distinguish two main forms of this online communication: (i) online explanations of medical procedures, and (ii) online commentary that describes or evaluates what the physician is seeing, feeling or hearing during the physical examination of the patient. Example 1 illustrates both online explanation (arrow 1) and online commentary (arrow 2): ${ }^{1}$ 
(1)

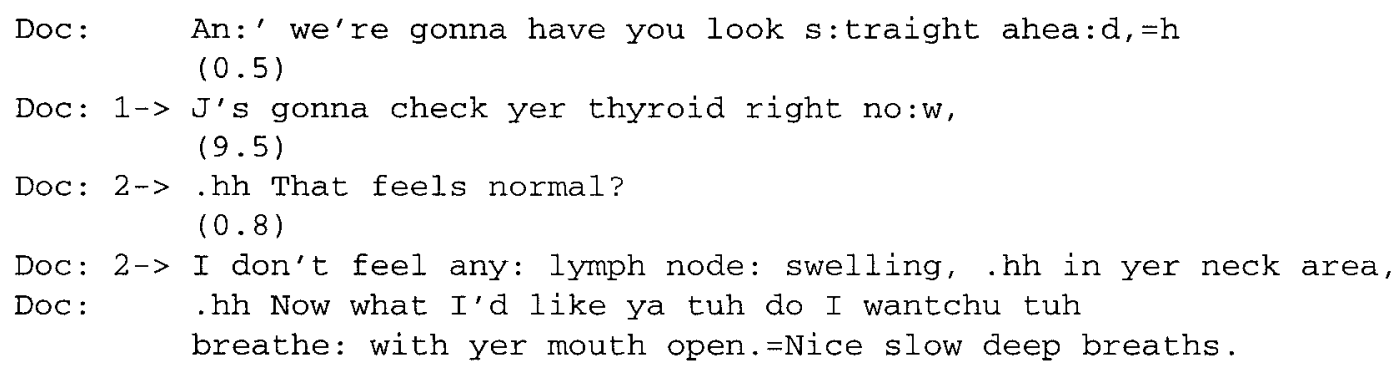

While the nature and function of online explanations are quite well understood and are recommended in current medical textbooks (Billings and Stoeckle, 1989; Zoppi, 1997; Swartz, 1998), ${ }^{2}$ the functionality of online commentary is less clear and opinions are more divided on the desirability of its use. The social science literature on physician-patient communication does not contain studies of the practice. ${ }^{3}$ Nonetheless we find that such commentary occurs relatively freely in adult and pediatric general practice consultations. This

\footnotetext{
${ }^{2}$ These textbooks generally recommend online explanations, counseling that such explanations have the effect of "reducing mystification, enhancing the patient's medical knowledge, and communicating respect by involving the patient in the care process" (Billings and Stoeckle, 1989, pp. 58-59). A recent study finds that physicians who "provided more orientation about the flow of the visit" were significantly less likely to be sued for malpractice, suggesting that online explanation is positively valued by patients (Levinson et al., 1997).

${ }^{3}$ In the only references that we have found in the literature, Byrne and Long (1976, p. 18) comment that "few doctors actually explain what they are doing when they examine patients physically, so much so that it is surprising to find a doctor who keeps up a running commentary on his work." They then give the following transcript (the online commentary is italicized): "Now then, this is a stethoscope. With it I can hear your heart and the air passing into your lungs. It might be a touch cold. Now then, deep breath. Good. I'm listening to your heartbeat now. Now then, deep breath. Now I'm listening to your lungs. They sound clear. Good." Similarly Roter and Hall (1992, pp. 83-84) include a specimen of online commentary, "Your blood pressure is great", under the coding category of 'positive talk'.

${ }^{4}$ See Peräkylä (1998a) for a discussion of related ways in which patients are given limited access to physician's diagnostic reasoning in a primary care context.

${ }^{5}$ The term 'diagnostic evaluation' will be used in preference to 'diagnosis'. With this broader term we mean to include events in which physicians pronounce patients to be well, or at least not suffering from an identifiable complaint, as well as the positive identification of a disease or complaint.
}

paper offers a description of online commentary as a communication practice, and outlines some of its functions in acute medical visits.

\section{Online commentary: a preliminary description}

As noted earlier, online commentary describes or evaluates the signs which physicians are encountering during the physical examination. In the process, the patient is afforded some access into the physician's diagnostic reasoning. ${ }^{4}$ However, although they are relevant to, and may foreshadow, the physician's final diagnostic evaluation, ${ }^{5}$ online comments are quite distinct from the concluding diagnosis or evaluation of the patient's health status. The distinction between online commentary and explicit diagnostic evaluations can be specified in two dimensions: content and positioning (see Table 1). In terms of content, online commentary differs from diagnosis in that it does not contain inferential reasoning in the form of conclusions about the patient's medical condition. Rather, online commentary simply formulates the sensory evidence that is available to the physician in the course of the medical examination. In terms of positioning, online commentary occurs during the physical examination of the patient. In contrast, diagnostic evaluation is typically produced as a distinct action constituting a discrete activity within the consultation (Byrne and Long, 1976; Heath, 1992). Thus, diagnostic evaluation is almost invariably spatially and temporally separated from the examination activity, and offered at its termination.

A further distinction can be made between online commentary and what we term 'prediagnostic commentary' (Stivers, 1998) in terms of content and positioning. In terms of content, prediagnostic commentary embodies inferences that anticipate a diagnostic conclusion. For example, at the conclusion of a patient's description of problems with her foot and prior to the physical examination, the physician remarks "I hope you didn't- may have uh s:mall fracture there er something.". Or again in a pediatric con- 
Table 1

Diagnostic evaluation, online commentary and pre-diagnostic commentary

\begin{tabular}{lll}
\hline & Content & Position \\
\hline Diagnosis & $\begin{array}{l}\text { inferences and conclusions about medical } \\
\text { observations } \\
\text { statements about what the physician observes, } \\
\text { feels etc. } \\
\text { Online commentary }\end{array}$ & $\begin{array}{l}\text { after physical examination, tests, etc. are } \\
\text { complete } \\
\text { during physical examination }\end{array}$ \\
Prediagnostic commentary & any point prior to the delivery of the diagnosis \\
\hline
\end{tabular}

sultation, after a brief initial glance at the patient and again prior to a physical examination, the physician comments to the parent that "He looks atopic". ${ }^{6}$ As these examples suggest, prediagnostic commentary is less restricted in its positioning than online commentary, occurring anywhere in the consultation prior to the diagnosis itself, including the very beginning of the consultation.

\section{Characteristics of online commentary}

Online commentary can be characterized not only in terms of its content and position relative to other forms of diagnostic talk, but also in terms of its design. We particularly note five characteristic features.

First, in contrast to diagnostic evaluations which are treated as a central activity in the consultation, physicians and patients treat online commentary as, at best, an intermission in and subordinate to the activity of examination which is under way. Online comments may occur simultaneously with an act of examination (for example, while the physician is performing an otoscopic examination of a patient's ear), or between successive elements in an examination comprising multiple actions (for example, examination of a patient's ears, throat and sinuses).

\footnotetext{
${ }^{6}$ The term 'atopic' refers to a hereditary tendency to develop immediate allergic reactions including asthma and atopic dermatitis.

${ }^{7}$ Some online comments may be used to confirm that a patient has a particular trouble. For example, during a stethoscopic examination of a patient with a very bad cough who has already been on a course of antibiotics, the doctor says, "You do have uh nasty sounding chest." Such confirmation may occasionally even be requested by a patient or parent. For example, in a pediatric case the parent had presented her son's problem as a "really bad cough" and had stated that "you can hear it in his chest an' everything when he tries tuh breathe." During the stethoscopic examination, after $5.0 \mathrm{sec}-$ onds the mother says "Hear it," requesting confirmation that the chest congestion exists.
}

Second, online commentary is most often used to report on signs that are absent or mild, and which are treated as nonserious by the physician. These comments, for example "That feels normal?" and "I don't feel any: lymph node: swelling, .hh in yer neck area," from (1) above, are apparently designed to offer reassurance to patients about their health status. We have yet to encounter online commentary that formulates the physician as encountering a potentially serious sign, or which describes a sign in serious terms. When serious or significant signs are encountered, they are generally not the subject of online commentary. ${ }^{7}$

Third, online comments can be divided into two broad types: (i) Online commentary that describes signs that are present but mild: this commentary ordinarily takes the form of a simple assertions, e.g., 'This is $\mathrm{X}$,' 'That's Y', normally using terms that are mild, downgraded or qualified, e.g, "That's a little bit red back there," or "there may be a little bit of lymph node swelling on this side compared to the other side". (ii) Online commentary that describes the absence of signs: this commentary is often mitigated by the use of 'evidential' formulations, e.g., "I don't see any fluid". Evidential formulations involve the use of verbs like 'see', 'feel', 'smell', 'hear', etc., which make reference to the sensory evidence from which observations come (Chafe and Nichols, 1986). They are a way of downgrading claims (Chafe, 1986). The claim "I don't see any fluid" is not as strong as "There isn't any fluid" because it leaves open the possibility of there being fluid which is unseen. The distribution of online commentary in relation to patient conditions, as discussed in points 2 and 3 , is summarized in Table 2 .

Fourth, online comments addressing both present and absent signs take two primary formats: (i) as reports of observations, "You can hardly feel the ovaries"; "I don't see any fluid"; "Little bit re:d ${ }^{\circ}$ " or (ii) as assessments of what is observed, "An' \#yer uterus is uh:\# (9.0) it's fine."; "Your ears look goo:d"; "This one looks perfect". In the report format, the physician does not formulate an overt evaluation about the significance of an observation for the patient's health status, leaving it to the patient to draw their own 
Table 2

Physical examination signs and physician comments during examination

\begin{tabular}{ll}
\hline Patient sign & Physician online comment \\
\hline Significant sign & no comment \\
Nonserious sign & simple assertion + minimizer, e.g. "There's a little redness there" \\
No sign & evidential assertion, e.g., "I don't see any redness there" \\
\hline
\end{tabular}

conclusions about it. In the assessment format, conclusions are overtly drawn.

Fifth, because online commentary occurs during the physical examination and is treated as subordinate to the activity of examination which is under way, it is rarely overtly addressed to patients or directly acknowledged by them. For example, online comments are typically delivered without gazing at the patient, which is a primary index of talk that is directly addressed to a recipient (Kendon, 1967; Goodwin, 1981). ${ }^{8}$ Online comments are generally not responded to by patients. Additionally, the patient may often be physically unable to respond during an examination (for example an otoscopic examination of the throat or sinuses). Moreover even when patients are physically able to respond, they generally lack access to what the physician is observing since frequently the examin-

\footnotetext{
${ }^{8}$ Of course, during online commentary the physician is often gazing at some part of the patient's body, for example, ears, throat, etc. This is to be distinguished from gazing at 'the patient' as a recipient of talk. Additionally, the patient under examination often assumes a 'middle distance look' (Heath, 1986), thus avoiding mutual gaze or joint observation of the part of the body under examination.

${ }^{9}$ We thank Health Care Partners Medical Group of Southern California for their help in permitting us to acquire some of our data.

${ }^{10}$ Professor Richard Street kindly allowed us to examine some cases from a hospital based internal medicine department in Texas, and Professor Douglas Maynard did the same for a set of similar cases in Wisconsin. Our free clinic Orange County data were generously made available to us by Dr. Virginia Elderkin Thompson and Professor Howard Waitzkin.

${ }^{11}$ The notable absence of online commentary among the resident sample may be accounted for by two considerations. (1) Because online commentary embodies an anticipation of diagnostic and treatment conclusions, its use may require a measure of experience that residents have not yet acquired. Moreover, (2) residents may be reluctant to broadcast their observations and anticipate their diagnostic conclusions during the examination, when both observations and conclusions may later encounter authoritative revision by the attending physician.
}

ations involve tools (e.g. otoscopes, stethoscopes, etc.), and their interpretation normally requires medical expertise (Peräkylä, 1998a). Thus the preconditions for response are absent (Pomerantz, 1984).

\section{Data}

The data used for this study comprise 150 videotaped pediatric consultations, and 185 videotaped adult primary care consultations from a total of 19 private practice physicians' offices. All the physicians are community based in the Southern California area. ${ }^{9}$ We also looked at a smaller number of videotaped consultations drawn from corpora of hospital based primary care in Texas and Wisconsin, and at a free clinic in Southern Californa staffed by residents. ${ }^{10}$ Online commentary occurred in all these environments, except the last. ${ }^{11}$ Online commentary was prominent in the pediatric data: in a subset of 50 acute and follow-up pediatric visits where antibiotic medication was a possible option, online commentary occurred in $76 \%$ of the cases.

\section{The contexts of online commentary: routine and acute medical visits}

\section{Routine visits}

As we have observed, most online commentary formulated signs as absent or mild, or reported on affirmative features of the patient's condition. This commentary, in describing the observations of an examination-in-progress, typically confirms and thus reassures patients that they are well. This function seems particularly clear in the case of physicals and other forms of 'well visits.' Here, where there is a series of examinations, and the presumption of each of them is that the patient is well and that there will be no diagnosis, the object of these kinds of online remarks is evidently reassurance that this is the case. For example, the data in (2) comes from a visit in which a patient has come in for her annual check-up. The physician is working through her bodily systems: 
(2) [Well visit - check up]

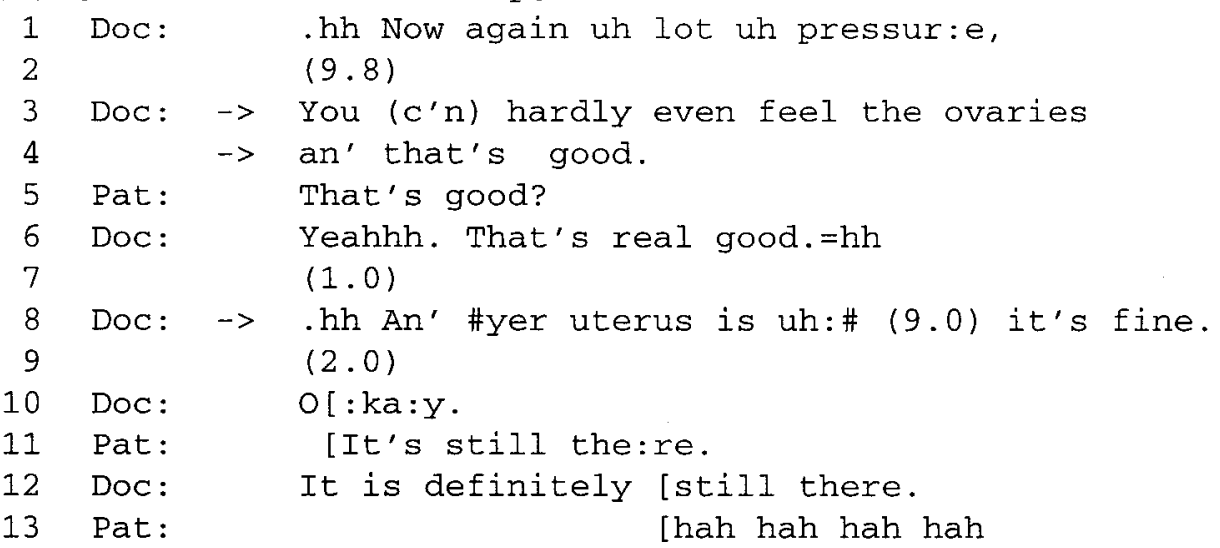

At line 3 the physician begins the online commentary in report format, describing what he can feel ("You (c'n) hardly even feel the ovaries") and, perhaps uncertain as to the inference the patient might draw, then offers an online assessment of that state of affairs as "good" (line 4). The assessment is clearly designed to be reassuring, and it effectively preempts any possible misapprehension by the patient about the physician's initial observation at line 3 . The physician appears to have been correct in his judgment that his initial comment could trigger a negative inference, because, at line 5 , the patient queries his subsequent assessment. In response, he further reassures the patient by upgrading his assessment to "real good" (line 6). At line 8, he offers a further positive assessment, this time of the patient's uterus. That the patient is reassured by the physician's remarks is evident, for example, in her humorous response (line 11) to his comment. ${ }^{12}$ In routine check-ups of all kinds (including the monitoring visits of older patients or those with chronic conditions), reassurance appears to be the primary purpose of nearly all the online commentary we observed.

\section{Acute visits}

Online commentary is also found in acute visits. For example, in (3), the physician is examining an eight year old boy with a sore throat and a cough. $\mathrm{He}$

\footnotetext{
${ }^{12}$ We note in passing that the patient's humorous remark evidences a residual 'working through' of the physician's earlier negatively formulated observation about her ovaries. This suggests that, for bodily domains where patients may be ignorant of what is expectable or desirable, online commentary that is based on absent signs may be more opaque when it is expressed in "report" rather than 'assessment' format.
}

describes his observations about the boy's throat at line 5 ("little bit re:d"), and the boy's ears at line 17 ("'at's fi:ne"). Subsequently, in lines 21-25/27, he summarizes his observations and offers a diagnostic conclusion $($ marked $=>$ ): the child has a cold.

Here, while the physician's online comments may have the effect of reassuring the mother, a more complex pattern of function may be involved. It is noticeable that the first of these online comments implicitly validates the mother's decision to bring the child to the physician. As the physician remarks, there is, after all, "a little redness." However the observation about the ears, together with the qualified nature of the 'redness,' indicates that the infection is not extensive. In this case, the parent can be reassured at the earliest possible opportunity (i.e., during the physical examination) both as to the correctness of bringing the child in for evaluation (line 5), and as to the essentially mild nature of the child's illness (line 17).

We propose that, by indicating the essentially mild nature of the child's signs, online commentary can function to justify and forecast (Maynard, 1996) the physician's upcoming diagnostic evaluation. In addition, online commentary may also forecast the range of treatments which might be recommended (e.g. over the counter remedies versus antibiotics or other prescription medication). By indicating that the child's condition is mild in (3), the physician may be heard to project that aggressive treatment is unnecessary. Thus online commentary may help to shape the parent's expectations toward an over the counter, rather than a prescription, treatment recommendation. The summary (lines 21-27) develops the online observations into a final evaluation: the child is sick (and, by implication, the parent was right to bring him in), but the illness is mild and “ce:rtainly doesn't need (.) penicillin ${ }^{\circ} \mathrm{r}$ anything like tha: $\mathrm{t}^{\circ}$ ".

This role of online commentary in forecasting mild 


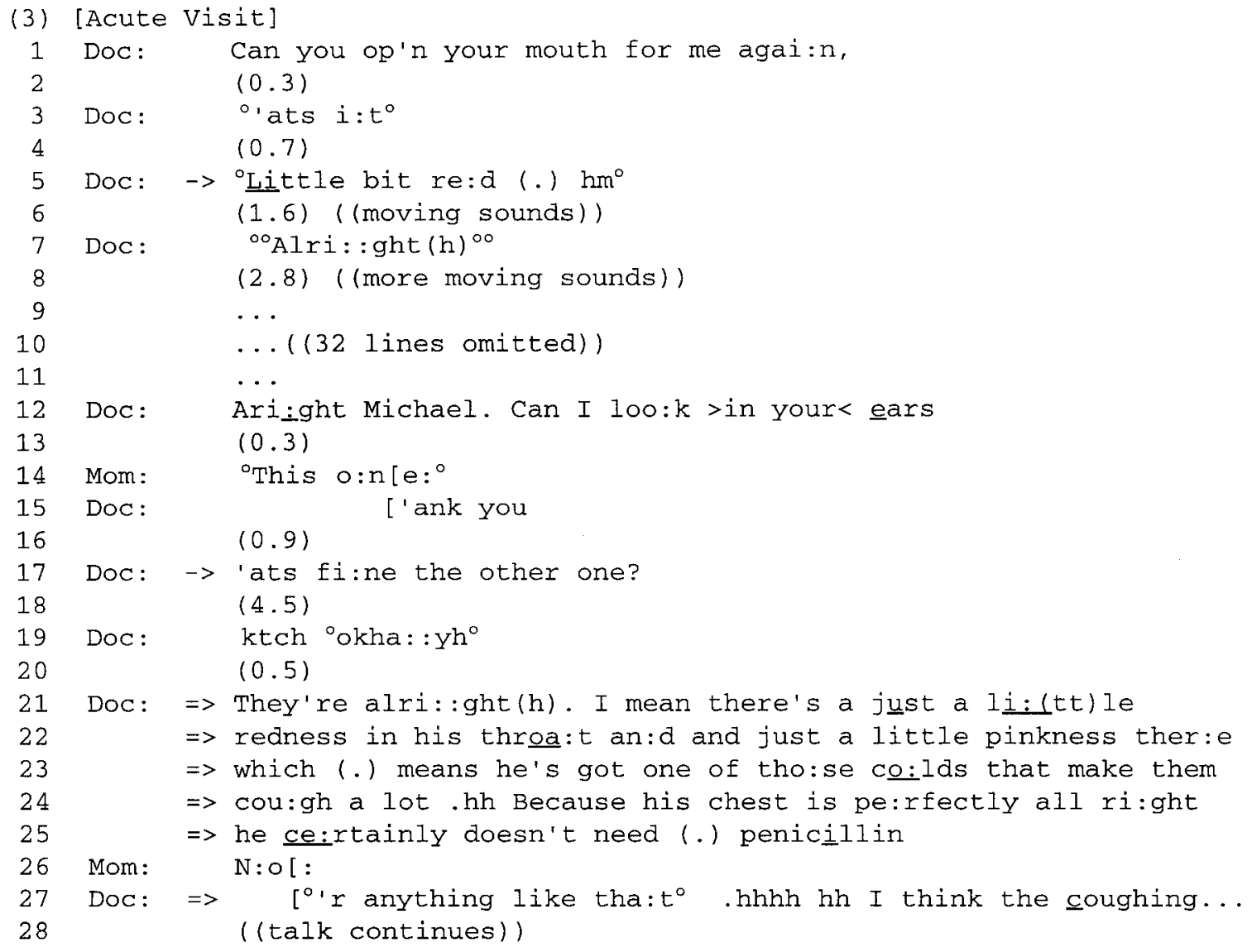

or 'no problem' diagnostic evaluations can be important for the physician. Physicians are frequently faced with circumstances in which patients may resist their diagnostic evaluations. Prominent among these are circumstances in which physicians must assert that patients' medical signs are unproblematic: they are mild or insignificant (or at least milder and less significant than patients have presented them to be); or alternatively that patient preferred treatments, such as prescription medications, are inappropriate. Under these circumstances, patients may be deprived of the perceived benefits of medication and other forms of medical treatment, and of authoritative medical support for their claim to financial and other benefits from entering the 'sick role' (Parsons, 1951; 1975; Freidson, 1970a, b). Patients also may feel vulnerable to the judgment that they were misguided in seeking medical assistance, are over-concerned about their own or their children's health, or in illegitimate search of 'secondary gains' from the sick role itself. ${ }^{13}$ As Heath

\footnotetext{
${ }^{13}$ For an account of patient orientations of this kind at the beginning of the medical consultation, see Heritage (in press).
}

(1992) and Peräkylä (1998a) have both documented, while patients are ordinarily passive in receiving diagnostic evaluations, they are more likely to be resistant when informed either that they do not have a problem, or that the problem is less severe than they had anticipated.

Under circumstances where a 'no problem' diagnostic evaluation must be delivered, physicians are faced with two potentially conflicting objectives. They need to assert the 'no-problem' evaluation (and/or recommend against prescription medication) so as to leave the patient in no doubt as to the medical judgment involved. However, second, they may want to communicate to the patient that they were right to seek medical advice and, more generally, prevent the patient from losing face because of what might otherwise be perceived as an over-eager pursuit of medical assistance. This second objective may mandate a less assertive informing than might be necessary to satisfy the first. That is, a physician who too strongly asserts that a patient's condition does not require treatment may risk being heard to imply that the patient was wrong or over-anxious in seeking medical assistance.

In his work on serious or life threatening conditions, Maynard (1996) has argued that patients find it easier 
to assimilate and accept adverse diagnoses if their general nature and 'valence' is forecast in advance. We propose that online commentary can have this effect in the context of 'no problem' diagnoses: forecasting the 'bad news' that the patient does not have a significant medical complaint, or has signs that are mild at worst, or cannot be efficaciously treated with prescription medication. We suggest that online commentary is a flexible resource, which can have the effect of forecasting a likely 'no problem' evaluation during the physical examination of the patient, while also noting consider- itially claims a continuing illness status, that he does not need further medication. In this case, an adult male patient is present for a second follow-up visit for a sinus infection. Although the patient has been given a substantial amount of medication, he complains of continuing sinus problems in the opening section of the consultation (line 6). Here, there is a developing disagreement between physician and patient which implicitly concerns, among other things, the prescription of further antibiotics:

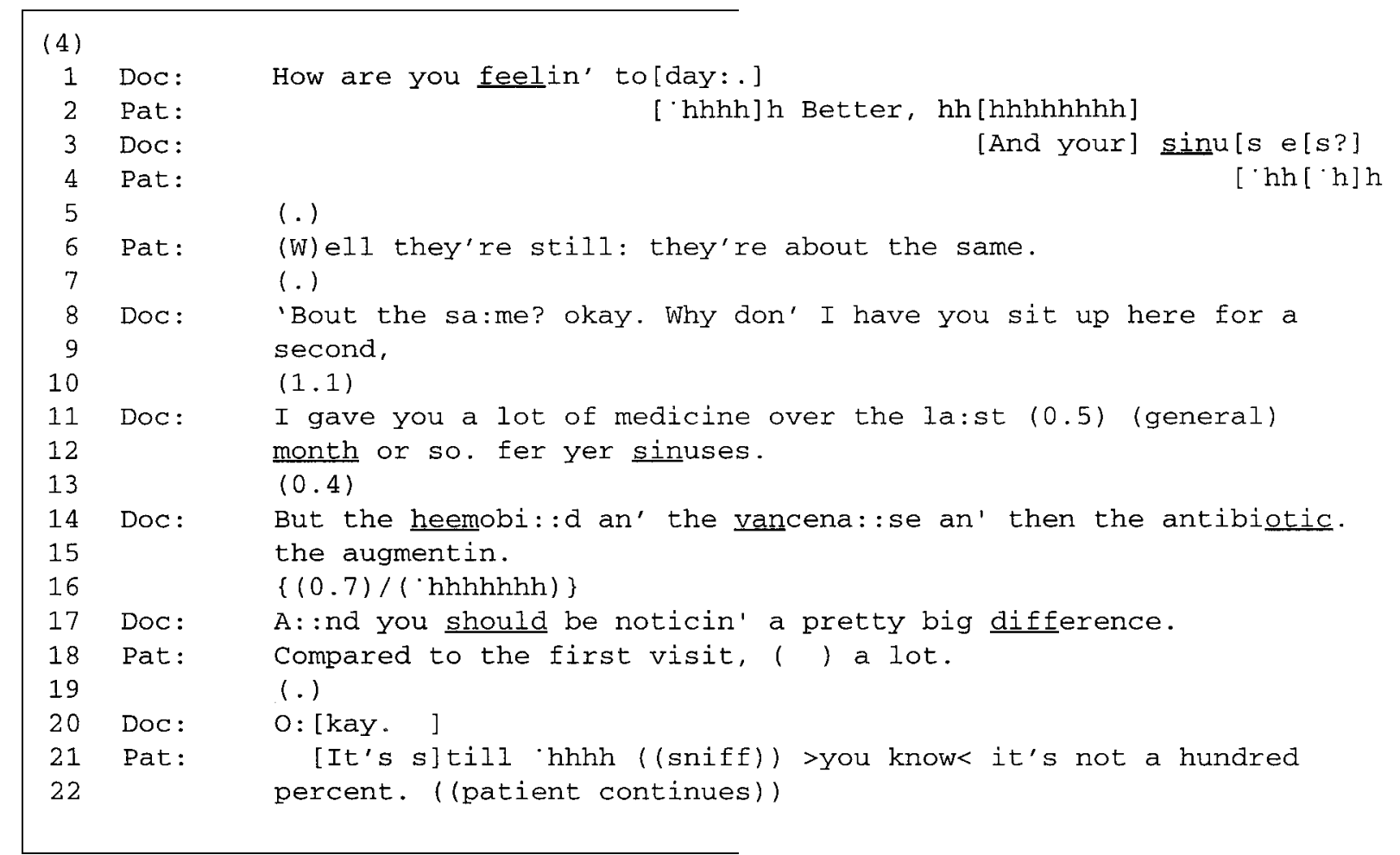

ations that justify the patient's decision to make the medical visit. In this way, online commentary can shape patient expectations towards the likelihood and legitimacy of a 'no problem' evaluation, and may preempt the emergence of conflicts during the final diagnostic evaluation.

In the remainder of this paper, we present two detailed case studies in which online commentary plays a role in shaping patient expectations so as to accept a 'no problem' diagnostic evaluation.

\section{Addressing patient resistance}

In the following case, online commentary is deployed in the course of convincing a patient, who in-
In response to the patient's assertion that his sinuses have not improved (line 6), the physician asserts that she has prescribed a lot of medication for the patient and lists them, remarking at line 17 that he "should be noticin' a pretty big difference." The word 'notice' here suggests the physician's belief that the patient may be better than he recognizes. The patient acknowledges some improvement (line 18), but still maintains a modified version of his position (lines 21-22): he is still not "a hundred percent."

The next section of the consultation involves the physical examination of the patient's ears (arrow 1), throat (arrow 2) and, finally, his sinuses (arrow 3). During or at the conclusion of each examination, and before her diagnostic evaluation, the physician comments online about what she is seeing: 


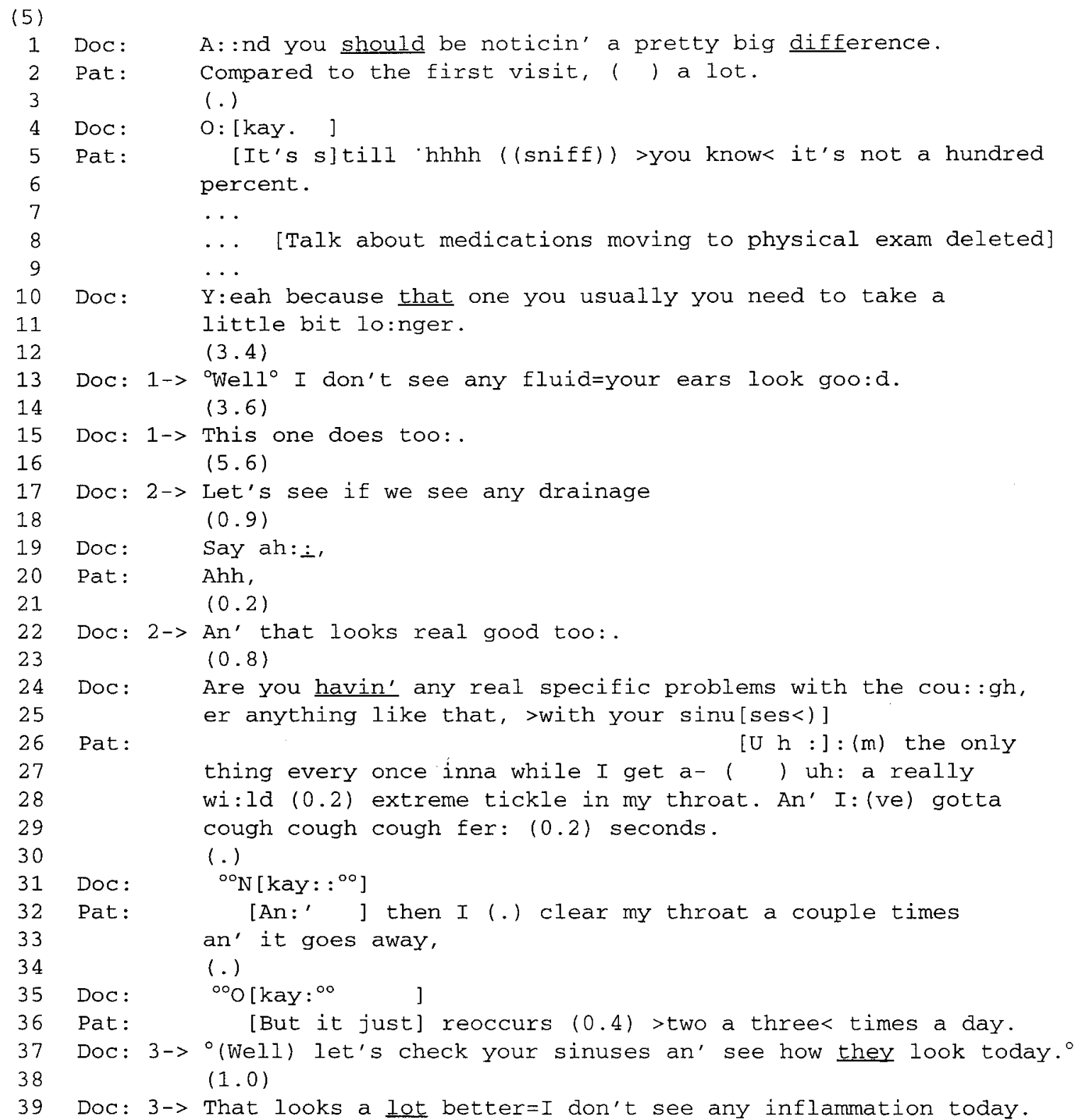

The physician's comments are uniformly favorable. They report observations which are positive from the standpoint of the patient's health status, but which conflict with the patient's earlier stated opinion that he is "not a hundred percent" (lines 5-6). The physician's initial online comment (line 13, arrow 1) comprises two units. The first ("Well ${ }^{\circ}$ I don't see any fluid") is a report formatted negative observation that, like many of this type, is evidentially formulated. It is preceded with "well," a marker that commonly prefaces disagreement and other disaffiliative actions (Pomerantz, 1984). The second unit ("your ears look goo:d.") is assessment formatted, and more explicitly takes a position. After she has examined the other ear, the physician builds from this first assessment to a second: "This one does too" (line 15). While her subsequent statements are still formulated in reduced, evidential terms, they are more explicit, summative, and cumulative. For example, the comment about the second ear "this one does too" is designed to be heard as a second to, and reinforcing of, her observations about the first ear. Her assessment of the patient's throat, "An' that looks real good too:." (line 22, arrow 2), is also built (with the "An", the repetition and upgrade of the eva- 
luative term (from "good" to "real good"), and the use of "too") to be heard as additional to, and reinforcing of, her comments about the patient's ears. All these later comments are in assessment format and embody a position that is, at the very least, implicitly opposed to the position that the patient had taken at the beginning of the consultation.

Finally, after a further short intervening verbal examination, the physician reaches the examination of the patient's sinuses, the main site where the patient had earlier asserted the existence of a continuing problem. She initiates the examination at line 37 , and case embodies a determination to reshape the patient's expectations about his condition from the earliest possible moment in the physical examination. Emerging from a context in which physician and patient were in disagreement about his wellness, each of these online comments is designed to support the physician's initial position that the patient should be "better." In several cases, the comments are managed so as to appear in definite contrast with the patient's claim that this is not the case.

These online comments form the basis for the physician's subsequent diagnostic evaluation:

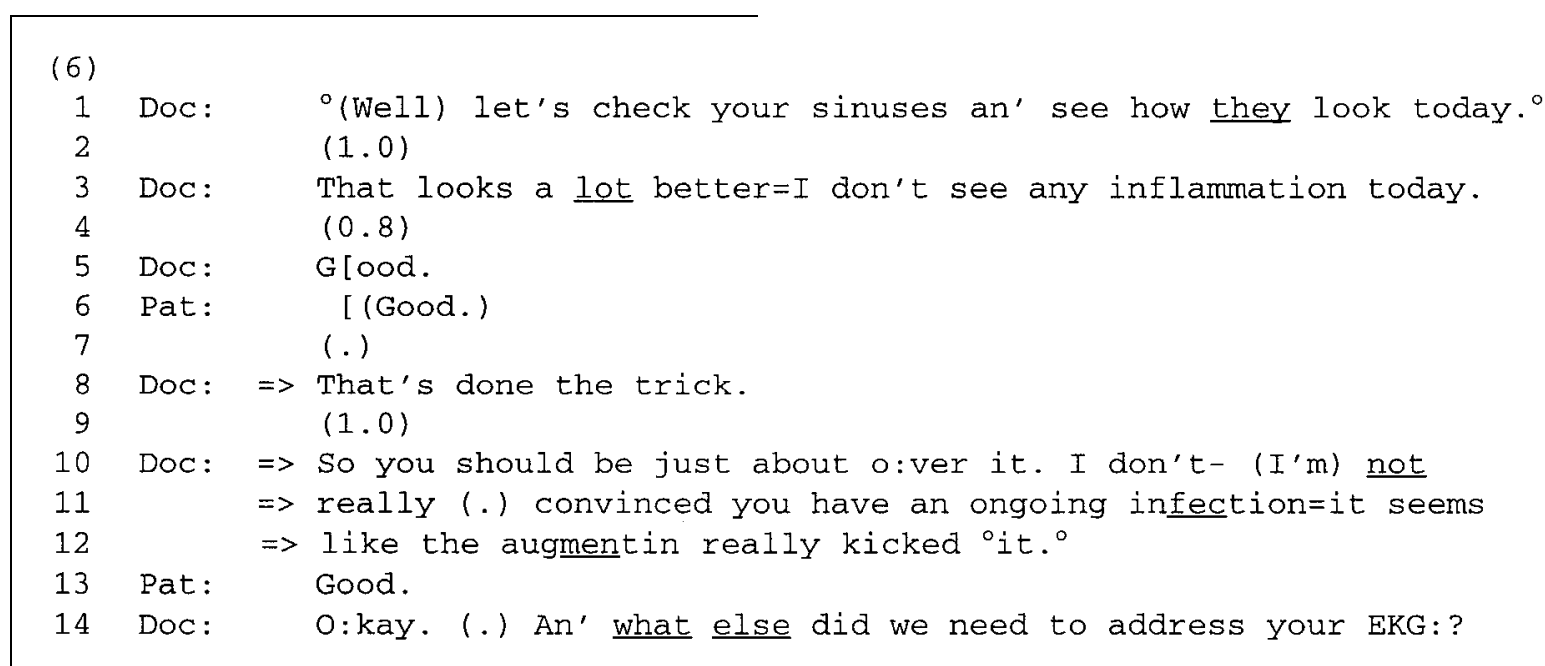

shortly thereafter, while still engaged in the examination, she offers an assessment: "That looks a lot better", adding the report formatted comment: "I don't see any inflammation today" (line 39, arrow 3). Once again, her comments are evidentially formulated. However the evaluative component of her first sentence is contrastive with the patient's initial evaluation, which employed the designedly downgraded descriptor "better" (see example (4), line 2). It is notable that the physician stresses the contrastive term "lot" in this sentence, thus underscoring the difference between her current evaluation and that offered by the patient. Her second comment "I don't see any inflammation today." offers a specific otoscopically visible detail in support of her first. In its design and in the manner and context of its delivery, this observation, while also evidentially formulated, is offered with real finality.

In contrast to (3) where the online commentary was designed to reassure an anxious parent and justify her decision to seek medical assistance for her child, this

\footnotetext{
${ }^{14} \mathrm{On}$ the role of idioms as 'finalizing' in the context of misalignments between interactants, see Drew and Holt (1998).
}

The physician's initial summative remark "That's done the trick" ((6) line 8) is said while turning from the patient and replacing the otoscope in its holder. It pulls together all the observations which accumulated across the physical examination. The indexical reference "that's" reaches back to invoke the patient's medication, which she earlier asserted (example (4), line 17) to be sufficient to make a "pretty big difference", as the subject of the sentence, while the remainder of the sentence deploys an idiom to describe the medication's success in treating the infection. ${ }^{14}$ After replacing the otoscope, the physician returns to face the patient, and more fully explicates this summary. Her opening statement is marked as an upshot or conclusion with "So" and the remainder of her sentence reinvokes her earlier statement to the effect that the patient "should be noticing a pretty big difference." Her next statement embodies a revision from a likely "I don't think..." format to a more judicial seeming, but oppositionally formulated, "I don't- (I'm) not really (.) convinced you have an ongoing infection". Here the term "convinced" makes reference to the series of examinations that she has made, while at the same time indicating that they do not support the 
patient's. In particular, it treats the patient as having taken the position that he has an ongoing infection, and thus indexes the opposition between her view, and the patient's earlier claims. The physician's final remark, though downgraded with the evidential "seems" returns to specify the "that's" in line 8 as the antibiotic augmentin, and her diagnostic evaluation that it "really kicked "it." depicts the impact of the antibiotic in terms that are both aggressive and final. It is inconceivable to the observers of this tape, and may well have seemed so to the patient, that the physician would have prescribed a further course of antibiotic treatment in this context. After the patient's acquiescent affiliation with her conclusions at line 13, the physician moves on to a next item of medical business, the patient's EKG assessment.

The interaction discussed in (4)-(6) clearly shows that the patient, who initially was prepared to counter the physician's position concerning his wellness, was by the end of the third segment (6), no longer prepared to do so. Looking back through the online commentary, we can find the roots of his acquiescence in his response to the third of the physician's online comments as, in overlap with the physician, he says "Good." (segment 6, line 6). ${ }^{15}$ Although this patient is unusual in the extent of his initial resistance to the physician's perspective, he is not unique in his subsequent acquiescence to a final 'no problem' diagnostic conclusion adumbrated by online commentary. In contrast to the cases discussed by Heath (1992) and Peräkylä (1998a) where patients resist 'no problem' diagnostic evaluations, all the cases involving online commentary in our data set are characterized by an absence of patient resistance during and after such evaluations.
What is the role of online commentary in this process? The physician's online commentary in (3) and (5) incorporates three features that make it difficult to resist:

1. The physician's comments about the patient's condition embody what Starr (1982, p. 14) calls the "cultural authority" of medicine: the physician is trained to look at ears, throats and sinuses, and she is professionally authorized to evaluate the state of these body organs for a living. From the layman's point of view, her observations define the state of these areas. She is culturally empowered to offer definitive conclusions. Patients are correspondingly not normatively entitled to contradict them. In a recent study of patients' argumentative responses to physicians' diagnoses, Peräkylä (1998b) found that patients never contradicted the evidence that physicians describe, even when they disagreed with their diagnoses.

2. Because these remarks are delivered while the examination is still in progress, they are not, as yet at least, conclusive. They are staging posts on the way to a conclusion. Further, they are observations that build up evidence incrementally, rather than asserting it conclusively. Thus, they are not to be treated, in themselves, as objects for discussion.

3. Finally, these comments often address areas of the patient's body, for example the ears and sinuses, that the patient is rarely if ever in a position to see, and which even the parent of a child would have difficulty in observing without an otoscope. Physicians have what we might term an "ecological advantage" in examining these areas, in that they are easily visible to physicians, but quite difficult for patients or others to examine.

\footnotetext{
${ }^{15} \mathrm{~A}$ further example in which the patient is even more explicit in drawing a 'no problem' conclusion for a series of online comments is the following. Here the physician's observation at line 3 is the $n$th in a long series of such comments:

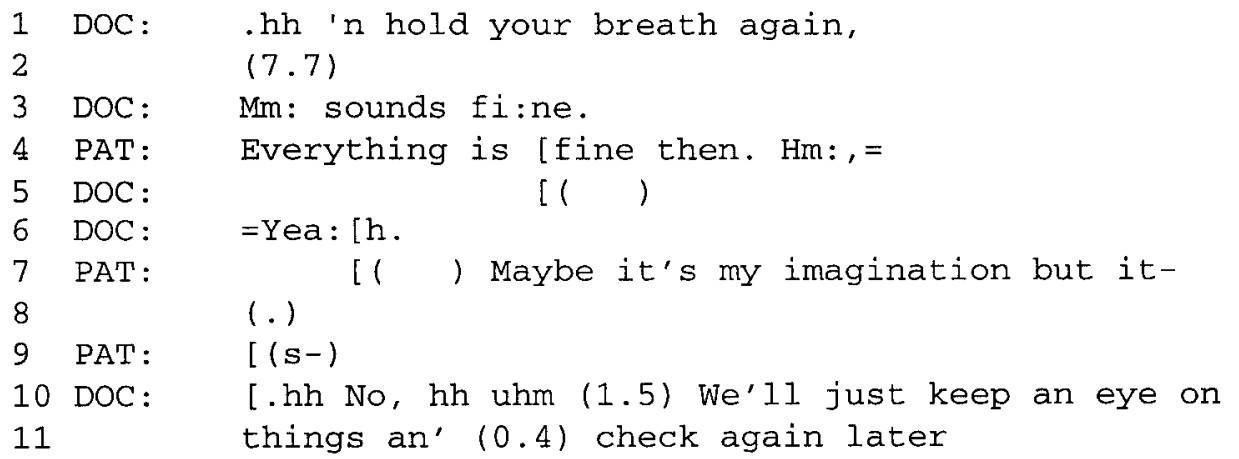

The patient's response at line 4 summarily evaluates the series of examinations and comments that the physician has made. Subsequently, at line 7 , she invokes the possibility that her symptoms are illusory. We thank Jeff Robinson for drawing our attention to this case. 
Thus in using online commentary, the physician in (4)-(6) effectively builds a case for the patient's relative wellness, piece by piece, and in a fashion that is extremely difficult for the patient to contradict. Whether consciously or not, by reporting each observation as it is made, the physician progressively builds a more or less unanswerable case for the diagnostic conclusions she ultimately asserts.

\section{Resisting patients while legitimizing the consultation}

Our final case shows a more complex management of a 'no problem' evaluation across an entire pediatric examination. In it we can see the pediatrician maintaining a careful balance between reassuring the mother that she was right to bring her child into the physician's office, while firmly resisting any implied expectation for antibiotic medication. This consultation with a girl aged 11 and her mother takes place on a Monday afternoon, and the child has already missed most of her school day. This context of the visit implies a strong initial claim to a significant medical problem and this is reinforced by the mother's problem presentation:

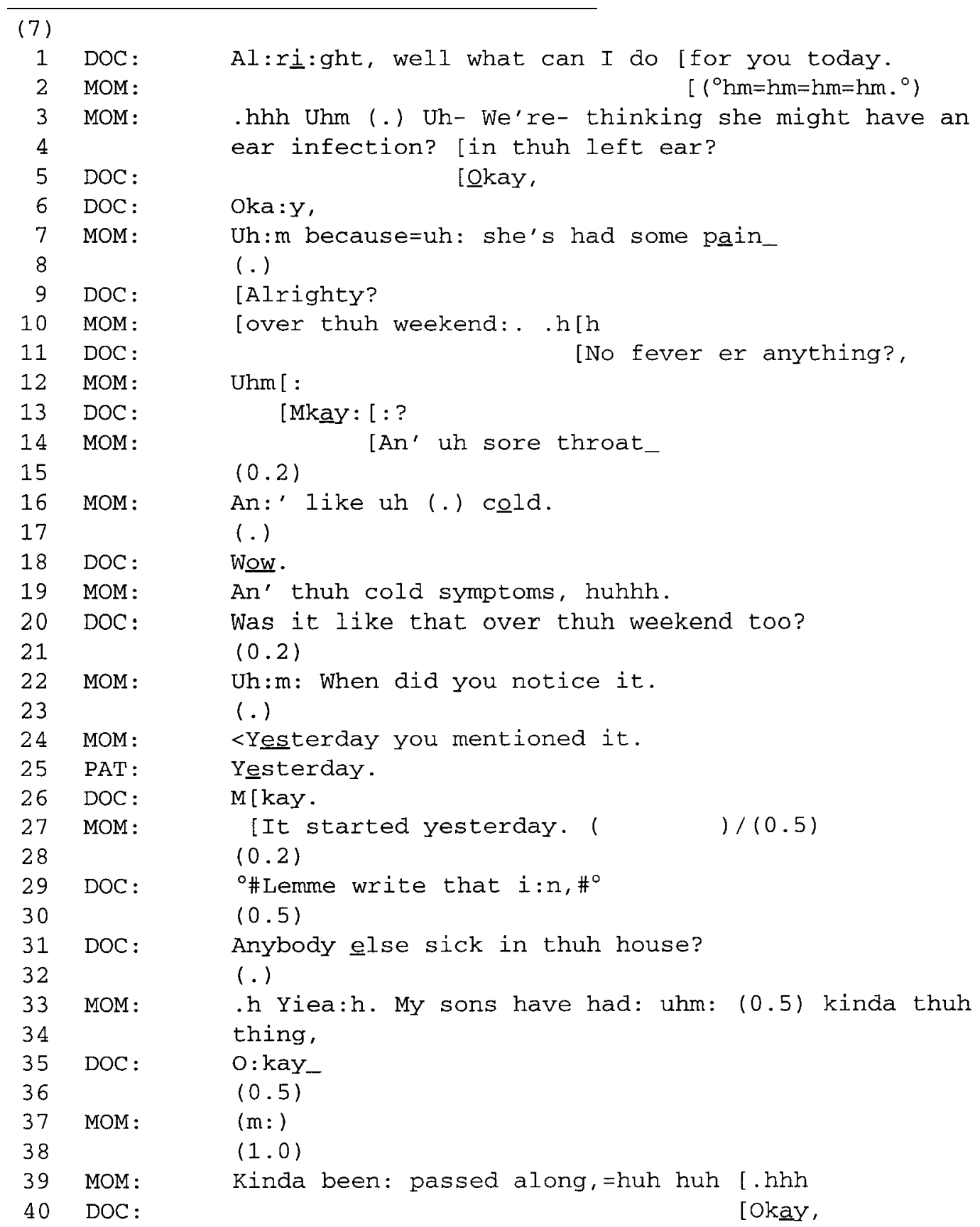


The mother's initial problem presentation, though couched in mitigated terms, conveys at least the following. (i) It identifies a diagnostic category for her child's problem ("an ear infection", line 4), and (ii) supports this claim with a specification of its location ("in thuh left ear", line 4), a symptom ("she's had some pain", line 7) and its duration ("over thuh weekend", line 10). Following the physician's question at line 11, the mother adds further symptoms, a sore throat (line 14) and cold symptoms (line 16/19). (iii) She indicates (with "We're- thinking") that the diagno- the mother and daughter collaborate over several turns at talk (lines 22-25), arriving at a response ("It started yesterday", line 27) that the mother fully endorses. Subsequently, the mother further presents an epidemiologic account for her daughter's condition ("Kinda been: passed along,", line 39) that further underscores her commitment to the significance of her daughter's complaint.

The pediatrician's examination of the girl commences shortly after (7) and begins with her ears, the site of the girl's chief complaint:

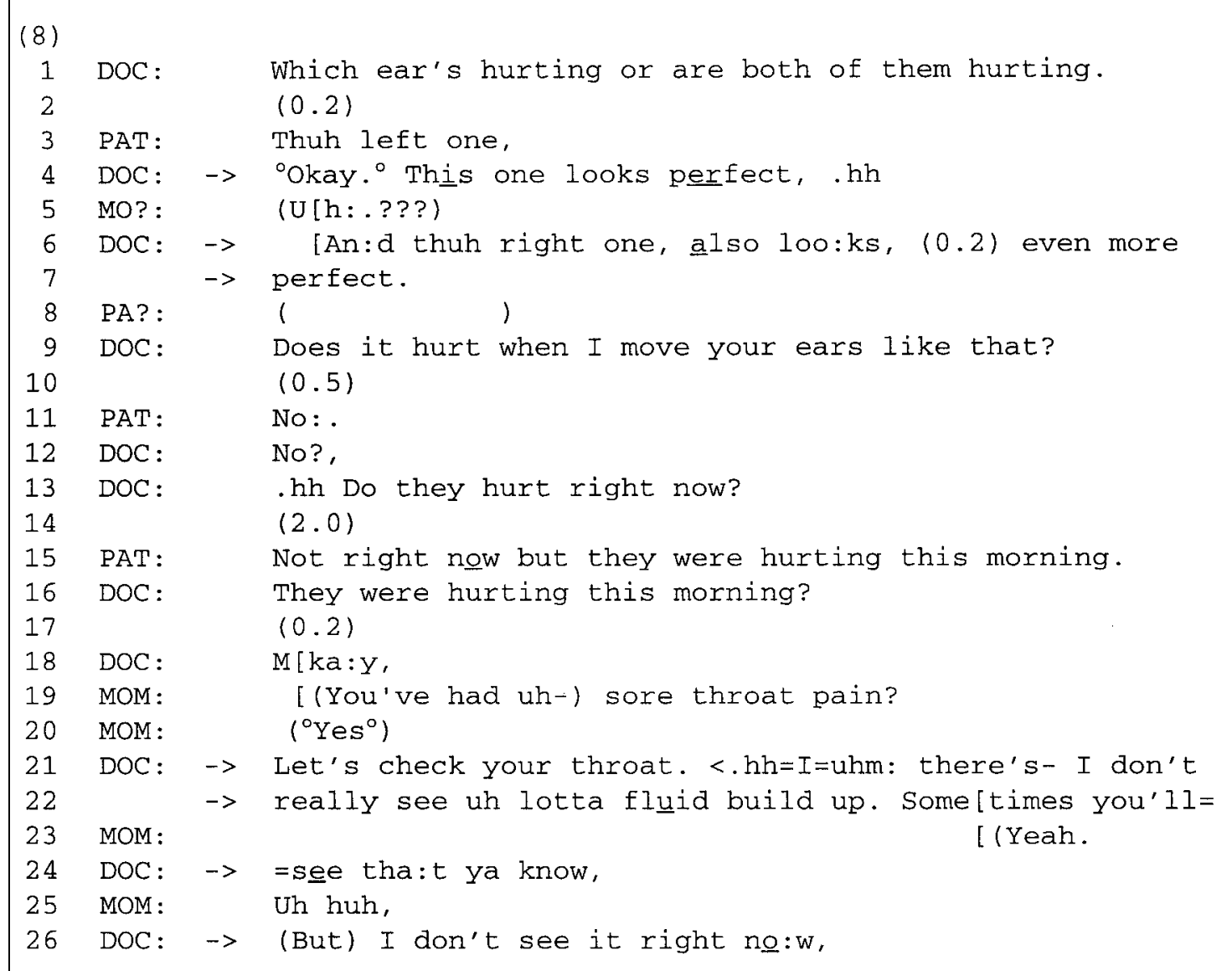

sis is an opinion which she shares with her daughter (and this formulation may invoke unnamed others in support of her claim). (iv) Whether she intends it or not, the mother's diagnostic reference to an "ear infection" is a formulation which is frequently understood by pediatricians to imply an unstated request for antibiotic medication. ${ }^{16}$

In answering the physician's further question about the duration of the most recently described symptoms,

\footnotetext{
${ }^{16}$ This observation is based on unpublished data from Rita Mangione-Smith MD, Department of Pediatrics, UCLA.
}

The left ear is the first to be examined. The physician's online commentary at line 4 , uttered during the otoscopic examination of the ear, embodies the evidential formulation that, as we have seen, is common when online commentary is deployed to counteract patient claims. A second online comment, uttered during the examination of the right ear, is built as a cumulative addition to his first and is deployed to similar effect. During further examination of the ears, the physician asks about current pain symptoms (lines 9, 12 and 13) finally eliciting a response (line 15) in which the girl defends herself (and her mother's prior claim, extract (7), line 7) against the possible inference that 
her symptoms are mild or nonexistent. At this point the mother intervenes with a question, overtly directed to her daughter about "sore throat pain" (line 19), which the physician treats as a request that he examine the daughter's throat (line 21). As he prepares for this, he returns with further online commentary about the state of the girl's ears (lines 21, 22, 24, 26) which embody an evidentially formulated denial of the kind of fluid build-up characteristically associated with middle ear infections. ${ }^{17}$ This denial includes two other mitigating elements. In characterizing fluid build-up as something you "sometimes" see, the pediatrician implies that this is not a criterial feature of ear pain.
Further, in adding that he does not "see it right now", he leaves open the possibility that fluid build-up may have been present in the past, or may appear in the future. $^{18}$

At this stage in the consultation, the effect of the physician's online commentary is to deny the existence of the main signs associated with the girl's chief complaint. Long before the problem discussion has been reached, he has implicitly undermined the candidate diagnosis presented by the girl and her mother at the consultation's opening.

The examination now proceeds to the girl's throat:

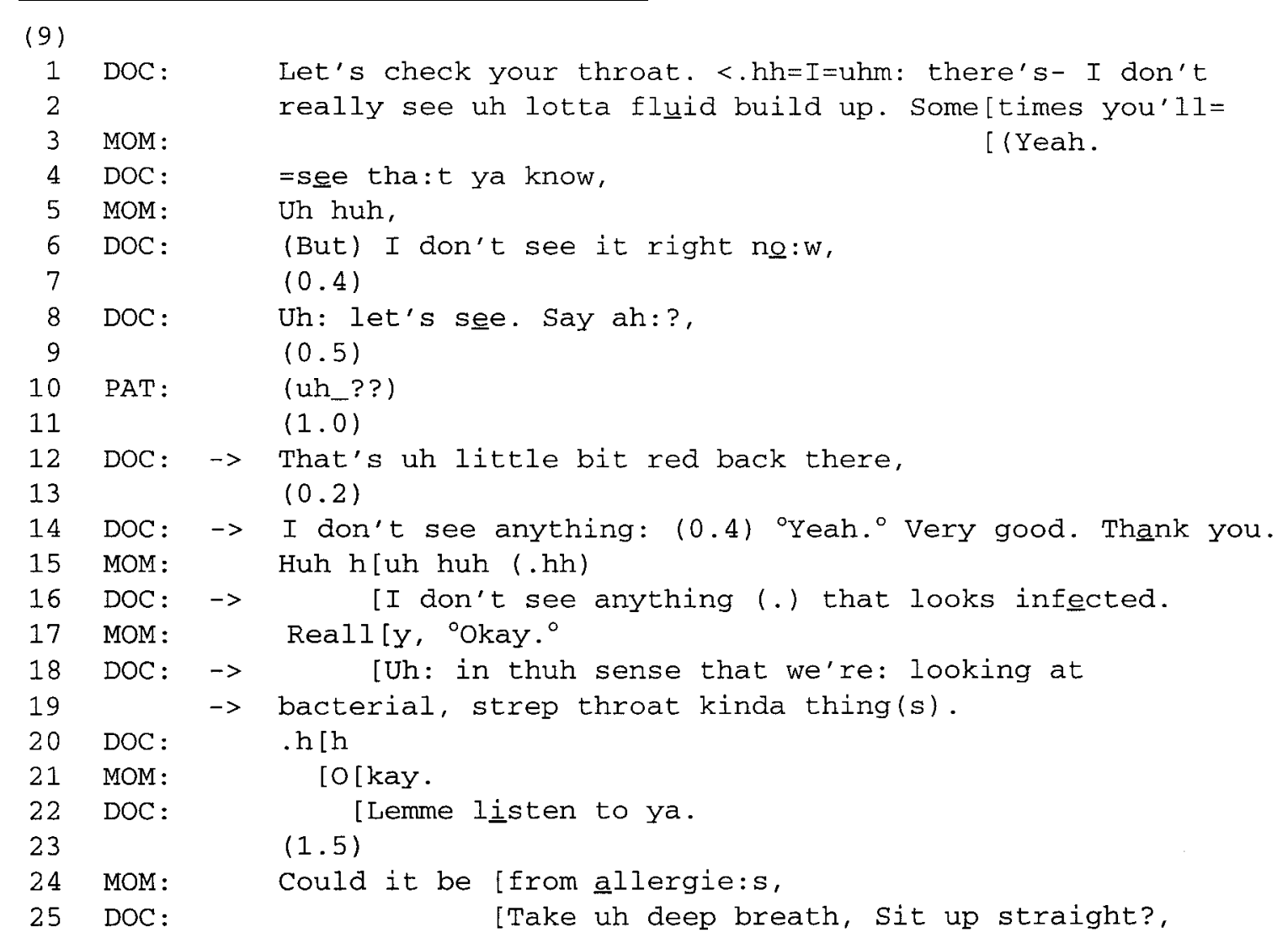

\footnotetext{
${ }^{17}$ It can be noticed that at line 21 , the pediatrician begins with "there's-" which initiates a simple assertion of the child's fluid build-up. He then cuts this off, in favor of the more mitigated evidential formulation "I don't really see". This kind of self-repair (Jefferson, 1974) is strong evidence of this physician's sensitivity to evidential formulation as a resource for mitigating diagnostic information that runs counter to the patient's claim to have a significant medical complaint.

${ }^{18}$ With respect to our comment about the past appearance of fluid build-up, we recognize that otitis media with effusion (the likely diagnosis invoked here) is unlikely to have appeared and resolved within such a short space of time. However, from the layperson's point of view, the pediatrician's remark may still be heard as implying this. It may be added that without an instrumentally assisted assessment of the tympanic membrane which the physician did not deploy in this examination, the physician would be unable to fully evaluate the presence or absence of fluid. This observation, of course, merely enhances our recognition of the physician's essentially rhetorical use of this piece of online commentary.
} 
This examination, initiated at line 8 , eventuates in a slight change of procedure in the physician's use of online commentary. At line 12, he observes a positive (but mild) symptom that could validate the child's complaint of "sore throat pain" and, with it, the decision to make the medical visit. Notably, this oberva- her acquiescence to the physician's rejection of "strep throat" as a diagnosis.

After an uneventful lung examination, the pediatrician moves to examine the girl's lymph nodes. This examination is shown in (10) below:

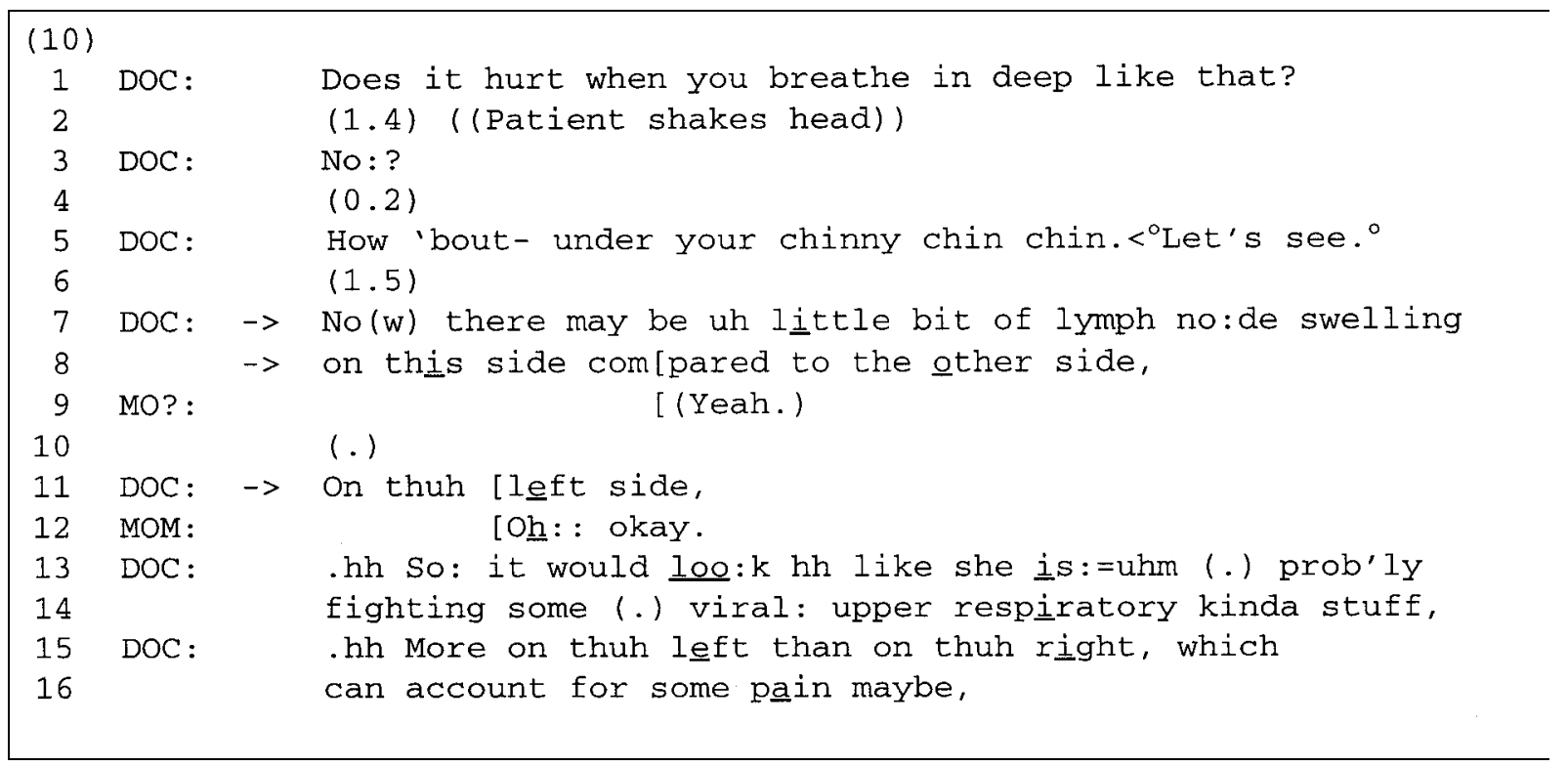

tion, which is supportive of the mother's decision to seek medical care for her child, is not downgraded via evidential formulation. Subsequently, having completed the examination and while preparing to listen to the girl's lungs, he produces a more comprehensive online assessment, which is also evidentially formulated: "I don't see anything (.) that looks infected." (line 16). Subsequent to the mother's possibly resistant "Really" (line 17), he qualifies his previous assessment, with a grammatically fitted increment (lines 18-19), in a way which both allows that the child may still have some kind of infection, while eliminating the prospect of a bacterial infection and, by implication, the prospect of antibiotic treatment.

The mother's response to this outcome at line 24 is to maintain her position that her daughter has a medically treatable problem, by raising the prospect of a alternative condition: allergies. Insofar as this inquires into a different diagnosis of the problem, it displays

\footnotetext{
${ }^{19}$ It is noticeable that the mother responds to this statement, which is supportive of her and her daughter's point of view, with a "marked acknowledgment" ("Oh okay"), a form of acknowledgment which patients deploy in other contexts where a provider's position converges with their own (Heritage and Sefi, 1992).
}

The outcome of this examination, albeit slightly downgraded with the modal "may" (line 7), offers some further support for the existence of a medical problem. The physician's identification of "lymph no:de swelling" is presented online, and gives implicit support to the patient's claim that she has experienced pain primarily on the left side. ${ }^{19}$ Subsequently the pediatrician makes this explicit in lines 15 and 16 as part of the diagnosis which he begins with the upshot formulating "so" at line 13.

The final diagnosis is offered in two parts which are separated by an extended compliment about the cleanliness of the child's ears: (see (11) opposite)

The first part of the problem discussion (the diagnostic evaluation in lines 1-4) is supportive of the mother and daughter's decision to seek medical care, and draws on earlier online comments (e.g., extract (10), lines 7-8/11) that were also supportive of that decision. The second half (lines 9-11, 15-16) builds from the adverse online commentary, especially that in (9), and clearly rejects antibiotic treatment in favor of symptomatic over the counter remedies. It is noticeable that the pediatrician begins his final treatment recommendation (lines 9-11) with the phrase "I would tell you though." In this way, he builds the recommendation as contrastive with the notion that viral conditions require antibiotic treatment, and hence in 
(11)

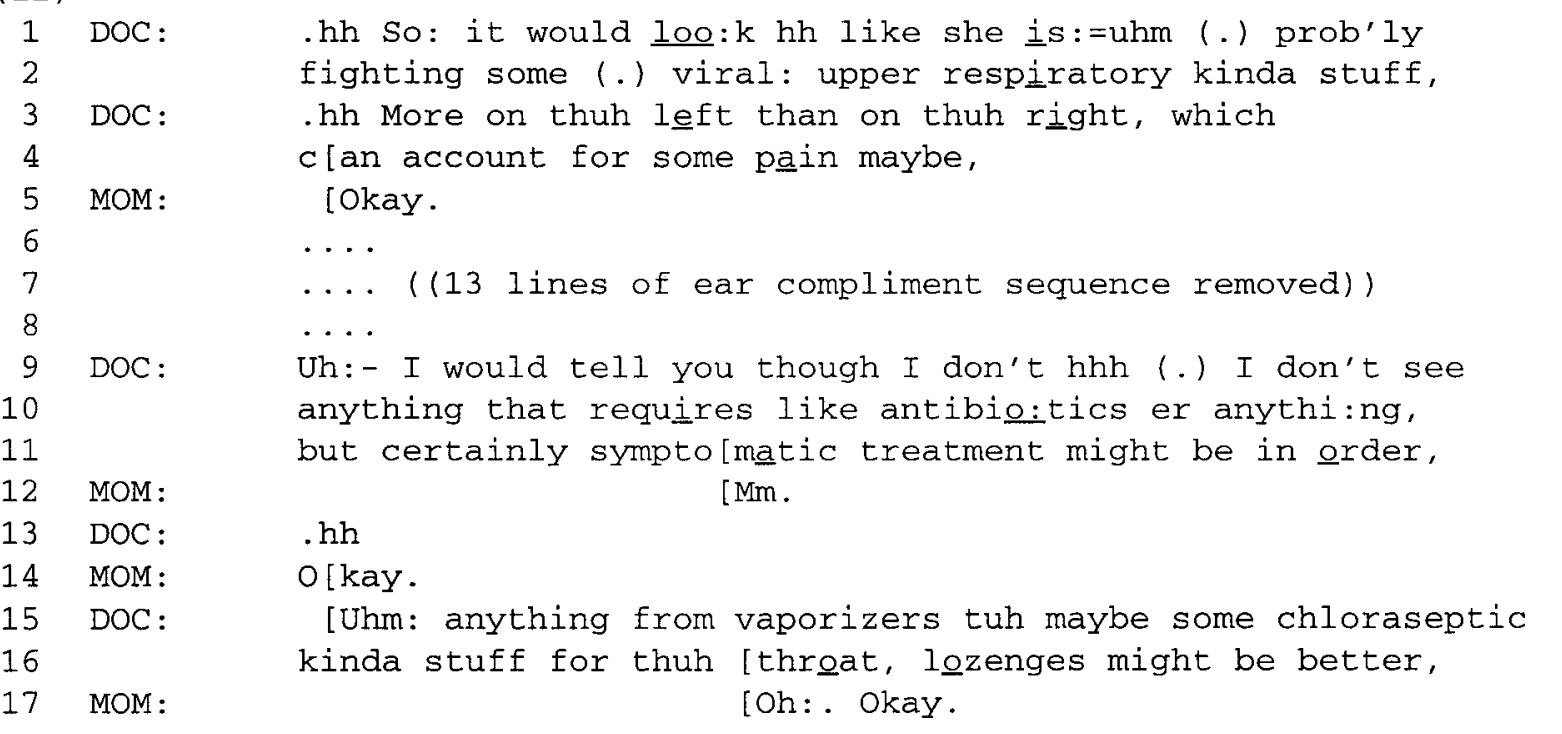

contrast with any position which the mother might hold in favor of antibiotic treatment, without contradicting his earlier evaluation (lines 1-4) that the child is nonetheless sick. His use of the evidential formulation ("I don't see anything...") revives the relevance of the observations reported in his earlier online comments, and reinvokes their significance as evidence for the position he is currently taking. Across this sequence, the mother responds to both the supportive and adverse aspects of the diagnostic evaluation with an acknowledgement token "okay" which accepts the physician's evaluation. At line 17, this acceptance becomes more marked with the addition of "oh" (Heritage and Sefi, 1992). Subsequent to this, the mother discusses the merits of several commercial remedies in a cordial way, and without contesting any aspect of the physician's conclusions.

As in the previous case involving sinuses, this interaction proceeds from a situation in which both the patient and her mother initially viewed the patient's complaint as significant and were defensive (extract (8), lines 15-16, 19, extract (9), line 24) when that stance seemed to be threatened, to a situation in which they acquiesced to the physician's conclusions without overt resistance or signs of disappointment. The role of online commentary in the progressive construction of powerful support for the physician's final diagnostic evaluation in this case seems clear. When online commentary is used, inferential resources for the diagnostic evaluation are built up incrementally. The result is a more persuasively formulated case for the final evaluation than would be obtained without the use of online commentary. Moreover, patients may have difficulty in contesting such evaluations without exhuming the online observations which they have already let pass.

\section{Discussion}

As noted earlier, medical textbooks are divided about the clinical value of online commentary. For example, Billings and Stoeckle (1989, p. 58-59) recommend that "when the examination is normal, let the patient know. Everyone appreciates this good news, both during the examination and at the end of the consultation." Zoppi (1997, p. 49) agrees that talk during the examination of the patient can serve a reassuring function: "physical findings should be described to the patient, who otherwise may misinterpret a squint and silence as cues that something ... is horribly wrong." A more cautious note is sounded by Bates et al. (1995, p. 117) who comment that while such remarks can increase "both the credibility and the conviction of the clinician's advice or reassurance", they also have drawbacks: "A steady series of reassuring comments, however, presents at least one potential problem: what to say when you find an unexpected abnormality. You may wish you had maintained a judicious silence earlier" (ibid, p. 116). Using similar reasoning, Swartz $(1998$, p. 88$)$ proposes a strongly negative view of this practice:

The examiner should always refrain from comments such as "That's good" or "That's normal" or "That's fine" in reference to any part of the examination. Although this is initially reassuring to the patient, if the examiner fails to make such a statement during another part of the examination, the patient will automatically assume that there is something wrong or abnormal. 
This paper has attempted to clarify some aspects of the nature and empirical incidence of online commentary in acute primary care visits. It suggests that online commentary is a communication practice that is relatively frequently used by physicians in acute visits. For the most part, the physicians in our data used online commentary to reassure patients about their health status. In particular, they responded to patient signs in the fashion described in Table 2, remaining silent in the face of significant signs of illness and, with some exceptions, ${ }^{20}$ giving online comments on mild or absent signs.

However, our analysis suggests that online commentary can serve functions that go beyond patient reassurance per se. Our data suggest that, regardless of whether they are overt or covert and of whether they are consciously intended or not, patients' problem presentations can convey demands for medical support and intervention that physicians may be obliged to resist. Clear cases of this situation are those in which the patient presents with symptoms which the physician cannot validate as signs of significant or treatable illness. For patients, the demand for medical intervention is often bound up with justifying the decision to seek medical assistance, and with the claim of personal reasonableness associated with that justification. In itself it is desirable that patients be firmly informed that their presenting problem is mild or insignificant, while also being reassured that it was reasonable to consult their physician. It is significant that online commentary tends to occur extensively in these environments. Through its use, whether intentionally or not, physicians can effectively build a case for a "no problem' evaluation, or against medical intervention, while reassuring patients of the rightness of their decision to seek medical assistance.

We conclude this discussion with the observation that prescription medication often stands at the crux of the conflict in perspective between physician and patient about the nature of patient symptoms and the necessity of medical intervention. A prescription of medication confirms that the patient was in fact sick

\footnotetext{
${ }^{20}$ There were significant differences among different physicians in terms of their general disposition to use online commentary in this data set.

${ }^{21}$ Survey data indicate that antibiotics are the second leading therapeutic category of drugs prescribed by office-based physicians in the United States (National Center for Heath Statistics, 1994). The use of amoxicillin and cephalosporins in pediatric cases increased substantially during the $1980 \mathrm{~s}$ (McCaig and Hughes, 1995).

${ }^{22}$ Studies of physicians' motivations to prescribe also suggest social and economic pressures as significant factors (Schwartz et al., 1989; Bradley, 1992).
}

and therefore that the patient (or caregiver) was right to seek medical attention; conversely a physician's decision not to prescribe medication may leave patients unsure as to whether their visit to the physician was justified. This concern is clearly manifested in the examples we have described in this paper. Concerns of this type may be further magnified in pediatric contexts where rapid onset illnesses can create anxiety, and where child patients who cannot sleep at night, or cannot go to school or day care during the day, impact the lives of their families in ways that sick adults do not. These contingencies add yet another source of pressure for parents to seek treatment, and doctors appear to be responsive to this pressure.

In a context of rising antibiotic prescription in the absence of bacterial infection, ${ }^{21}$ patient expectations have a substantial impact on physician's prescribing behavior. In adult primary care contexts, studies indicate that patients who expect antibiotic medication are $30-40 \%$ more likely to receive it than patients who do not (Virji and Britten, 1991; Webb and Lloyd, 1994). ${ }^{22}$ In the pediatric context, Mangione-Smith et al. (1999) have shown that physicians' perceptions of parental expectations for antibiotics were the only significant predictor of their prescribing antibiotics for conditions of presumed viral etiology. They also found that when physicians perceived parents to want antibiotics, they gave a bacterial diagnosis $70 \%$ of the time in contrast with $31 \%$ of the time when physicians did not perceive parents as wanting antibiotics. All the acute cases discussed in this paper ((3), (4)-(6), (7)-(11)) involve the physician's explicit rejection of the relevance of antibiotic treatment. If these case study findings can be generalized, online commentary may prove to be a simple but powerful communication resource with which physicians can resist implicit or explicit patient pressure for antibiotic medication. Further study is undoubtedly necessary to clarify this possibility.

\section{Acknowledgements}

We would like to thank Steven Clayman, Rita Mangione-Smith, Anssi Peräkylä, Andrew Roth, Manny Schegloff and especially Jeff Robinson for their comments on an earlier draft of this paper.

\section{References}

Atkinson, J.M., Heritage, J. (Eds.), 1984. Structures of Social Action: Studies in Conversation Analysis. Cambridge University Press, Cambridge.

Bates, B., Bickley, L.S., Hoekelman, R.A., 1995. Physical examination: approach and overview. In: Bates, B., Bickley, L., Hoekelman, R. (Eds.), Physical Examination 
and History Taking, 6th ed. J.B. Lippincott, Philadelphia, PA, pp. 115-135.

Billings, J.A., Stoeckle, J.D., 1989. The Clinical Encounter: A Guide to the Medical Interview and Case Presentation. Year Book Medical Publishers, Chicago, IL.

Bradley, C.P., 1992. Uncomfortable prescribing decisions: a critical incident study. British Medical Journal 304, 294 296.

Byrne, P.S., Long, B.E.L., 1976. Doctors Talking to Patients: A Study of the Verbal Behaviours of Doctors in the Consultation. HMSO, London.

Chafe, W., 1986. Evidentiality in English conversation and academic writing. In: Chafe, W., Nichols, J. (Eds.), Evidentiality: The Linguistic Coding of Epistemology. Ablex, Norwood, NJ, pp. 261-272.

Chafe, W., Nichols, J. (Eds.), 1986. Evidentiality: The Linguistic Coding of Epistemology. Ablex, Norwood, NJ.

Drew, P., Holt, E., 1998. Figures of speech: idomatic expressions and the management of topic transition in conversation. Language in Society 27 (4), 495-523.

Freidson, E., 1970a. Profession of Medicine: A Study of the Sociology of Applied Knowledge. University of Chicago Press, Chicago.

Freidson, E., 1970b. Professional Dominance. Aldine, Chicago.

Goodwin, C., 1981. Conversational Organization: Interaction Between Speakers and Hearers. Academic Press, New York.

Heath, C., 1986. Body Movement and Speech in Medical Interaction. Cambridge University Press, Cambridge.

Heath, C., 1992. The delivery and reception of diagnosis and assessment in the general practice consultation. In: Drew, P., Heritage, J. (Eds.), Talk at Work. Cambridge University Press, Cambridge, pp. 235-267.

Heritage, J. Accounting for the visit: patients' reasons for seeking medical care. In: Heritage, J., Maynard, D. (Ed.), Practicing Medicine: Talk and Action in Primary Care Consultations. Cambridge University Press, Cambridge. In press.

Heritage, J., Sefi, S., 1992. Dilemmas of advice: aspects of the delivery and reception of advice in interactions between health visitors and first time mothers. In: Drew, P., Heritage, J. (Eds.), Talk at Work. Cambridge University Press, Cambridge, pp. 359-417.

Jefferson, G., 1974. Error Correction as an Interactional Resource. Language in Society 2, 181-199.

Kendon, A., 1967. Some functions of gaze-direction in twoperson conversation. Acta Psychologica 26, 22-63.

Levinson, W., Roter, D., Mullooly, J.P., Dull, V.T., Frankel, R.M., 1997. Physician-patient communication: the relationship with malpractice claims among primary care physicians and surgeons. JAMA 277 (7), 553-559.

Mangione-Smith, R., McGlynn, E., Elliott, M., Krogstadt, P., Brook, R., 1999. The relationship between perceived par- ental expectations and pediatrician antimicrobial prescribing behavior. Pediatrics 103, 711-718.

Maynard, D., 1996. On 'realization' in everyday life. American Sociological Review 60 (1), 109-132.

McCaig, L.F., Hughes, J.M., 1995. Trends in antimicrobial drug prescribing among office-based physicians in the United States. Journal of the American Medical Association 273, 214-219.

National Center for Health Statistics, 1994. National Ambulatory Medical Care Survey, 1989, 1992. National Technical Information Service, Washington, DC.

Ochs, E., Schegloff, E.A., Thompson, S.A. (Eds.), 1996. Interaction and Grammar. Cambridge University Press, Cambridge.

Parsons, T., 1951. The Social System. Free Press, New York.

Parsons, T., 1975. The sick role and the role of the physician reconsidered. Milbank Memorial Fund Quarterly 53, 257 278.

Peräkylä, A., 1998a. Authority and accountability: the delivery of diagnosis in primary health care. Social Psychology Quarterly 61 (4), 301-320.

Peräkylä, A., 1998b. Agency and authority: extended responses to diagnostic statements in primary care encounters. Unpublished mimeo, University of Tampere, Finland.

Pomerantz, A., 1984. Agreeing and disagreeing with assessments: some features of preferred/dispreferred turn shapes. In: Atkinson, J.M., Heritage, J. (Eds.), Structures of Social Action: Studies in Conversation Analysis. Cambridge University Press, Cambridge, pp. 57-101.

Roter, D., Hall, J., 1992. Doctors Talking with Patients/ Patients Talking with Doctors: Improving Communication in Medical Visits. Auburn House, Westport, CT.

Schwartz, R.K., Soumerai, S.B., Avorn, J., 1989. Physician motivations for nonscientific drug prescribing. Social Science \& Medicine 28, 577-582.

Starr, P., 1982. The Social Transformation of American Medicine. Basic Books, New York.

Stivers, T., 1998. Pre-diagnostic commentary in veterinarianclient interaction. Research on Language and Social Interaction 31 (2), 241-277.

Swartz, M.H., 1998. The physical examination. In: Swartz, M.H. (Ed.), Textbook of Physical Diagnosis: History and Examination, 3rd ed. W.B. Saunders, Philidelphia, PA, pp. 85-91.

Virji, A., Britten, N., 1991. A study of the relationship between patients' attitudes and doctors' prescribing. Family Practice 8, 314-319.

Webb, S., Lloyd, M., 1994. Prescribing and referral in general practice: a study of patients' expectations and doctors' actions. British Journal of General Practice 44, 165-169.

Zoppi, K.A., 1997. Interviewing as clinical conversation. In: Mengel, M.B., Fields, S.A. (Eds.), Introduction to clinical skills: A patient-centered textbook. Plenum Medical Books, New York, NY, pp. 41-55. 